\title{
Kontribusi Desa Wisata Sendang Duwur Kabupaten Lamongan Terhadap Ekonomi Masyarakat Lokal
}

Ursulla Mariska Maduma Silaban a,1, Saptono Nugroho a,2

1ursullasilaban@gmail.com,2saptono_nugroho@unud.ac.id

aProgram Studi S1 Destinasi Pariwisata, Fakultas Pariwisata,Universitas Udayana, Jl. Dr. R. Goris, Denpasar, Bali 80232 Indonesia

\section{ABSTRACT}

Location of this research in Sendang Duwur district of Lamongan. The condition of tourism Sendang Duwur Village have big potential in giving economic contribution to local society. This is the purpose of this research.

Based on the above research that revealed three problems, namely what the uniqueness from tourism product in Sendang Duwur Village, how was the tourist shopping behavior in Sendang Duwur Tourism Village, And how was contribution of Sendang Duwur Tourism Village for Local Comunnity Economic. To express the above problem this research using primary and secondary data source, while type of data used is the qualitative data and quantitative data. The technique in order to obtain the validity of data using flow model method and quantitative analyzing. Data which collect by questionnaire, in-depht interview, observation and documentation.

The results of this study related to tourism product unique of Sendang Duwur Tourism Village as attraction, amenities, accessibility and ancillary services. The type of tourist shopping behavior is tourist who like to look for variety with percentage of $80 \%$. Sendang Duwur Tourism Village has not contributed optimally to improve community local economic because visitor spending whose amount is determind by length of stay cannot be used because there is no tourist staying. Tourist only make shorts visit.

Some advice will be given for the local people so that keep specificity of tourism product. For the government to more active to promote Sendang Duwur Village to be known to many people.

Keywords : contribution economy, tourism village, local community

\section{PENDAHULUAN}

Pariwisata merupakan salah satu industri penggerak perekonomian suatu negara. Perekonomian Indonesia juga mengalami peningkatan karena didukung aktifitas sektor pariwisata dari aktifitas wisatawan. Berkembangnya sektor pariwisata dapat memberikan manfaat ekonomi khususnya kepada masyarakat lokal yang tinggal di kawasan pariwisata. Desa wisata merupakan salah satu bentuk kegiatan pariwisata yang dapat memberikan manfaat dan kesejahteraan khususnya pada masyarakat lokal. Pengembangan desa wisata merupakan kegiatan yang efektif dalam membangun suatu desa dan mengangkat perekonomian masyarakat pedesaan karena pengembangan kegiatan pariwisata nya memanfaatkan nilainilai tradisional suatu desa sebagai daya tarik wisata, terciptanya lapangan pekerjaan baru bagi masyarakat lokal sehingga masyarakat lokal dapat berperan aktif dalam perkembangan pariwisata di desa nya serta ikut merasakan hasil dari kegiatan pariwisata tersebut.

Salah satu desa di Kabupaten Lamongan yang mulai berkembang dalam sektor wisatanya adalah Desa Wisata Sendang Duwur. Desa Sendang Duwur memiliki potensi wisata yang mampu menarik kunjungan wisatawan ke Kabupaten Lamongan. Desa Wisata Sendang Duwur sendiri sejak dahulu dikenal sebagai salah satu desa penghasil kerajinan tangan seperti batik, sulam bordir dan aneka perhiasan emas. Lokasinya dekat dengan tempat wisata yang cukup populer di Lamongan yaitu Wisata Bahari Lamongan, Maharani Zoo dan makam Sunan Drajat. Desa Wisata Sendang Duwur memiliki potensi yang cukup besar dalam memberikan kontribusi ekonomi khususnya pada masyarakat lokalnya. Apabila wisatawan datang ke Desa Sendang Duwur mereka dapat membelanjakan uang mereka untuk membeli cinderamata khas Lamongan. Hal ini akan memberikan dampak terhadap peluang kerja dan tingkat pendapatan pengerajin. Selain itu dapat dilihat pula pada tabel 1.1 mengenai jumlah wisatawan yang datang ke Makam Sendang Duwur yang terdapat di desa Sendang Duwur pada tahun 2016. 
Tabel 1.1 Jumlah Kunjungan Wisatawan ke Daya Tarik Wisata Kabupaten Lamongan

\begin{tabular}{|c|c|c|c|}
\hline \multirow[t]{2}{*}{ No } & \multirow[t]{2}{*}{ Daya Tarik Wisata } & \multicolumn{2}{|c|}{ Jumlah (org) } \\
\hline & & Wisnus & Wisman \\
\hline 1 & $\begin{array}{ll}\text { Gua } & \text { Maharani } \\
\text { (Mazoola) } & \end{array}$ & 288.562 & 76 \\
\hline 2 & $\begin{array}{ll}\text { Makam } & \text { Sendang } \\
\text { Duwur } & \\
\end{array}$ & 91.917 & 0 \\
\hline 3 & Makam Sunan Drajat & 485.811 & 0 \\
\hline 4 & Museum Drajat & 437.753 & 0 \\
\hline 5 & Waduk Gondang & 80.890 & 0 \\
\hline 6 & $\begin{array}{ll}\text { Wisata } & \text { Bahari } \\
\text { Lamongan } & \\
\end{array}$ & 582.576 & 107 \\
\hline 7 & Brumbun & 28.381 & 0 \\
\hline 8 & $\begin{array}{l}\text { TPI dan Monumen } \\
\text { Vanderwijk }\end{array}$ & 367.759 & 0 \\
\hline & Jumlah Total & 2.363 .649 & 183 \\
\hline
\end{tabular}

Sumber: Dinas Pariwisata Daerah Kabupaten Lamongan Tahun 2016

Dilihat dari tabel 1.1 Desa Wisata Sendang Duwur cukup berpotensi memberikan kontribusi terhadap kepariwisataan di Kabupaten Lamongan. Dari tabel tersebut diketahui bahwa Wisata Bahari Lamongan (WBL) merupakan daya tarik wisata yang paling besar jumlah kunjungan wisatawannya pada tahun 2016 yaitu sebanyak 582.576 orang wisatawan nusantara dan 107 wisatawan mancanegara, di posisi kedua ada Makam Sunan Drajat sebanyak 485.811 orang wisatawan nusantara. Kemudian dari delapan daya tarik wisata diatas makam sendang duwur yang merupakan ikon Desa Wisata Sendang Duwur sendiri berada diposisi keenam yang dikunjungi wisatawan dengan jumlah sebanyak 91.917 wisatawan nusantara pada tahun 2016. Bagi sebuah desa wisata yang baru berkembang, Desa Wisata Sendang Duwur cukup berpotensi memberikan kontribusi terhadap kepariwisataan di Kabupaten Lamongan. Jika segenap stakeholder pariwisata mau bersamasama membangun dan meningkatkan kepariwisataan Desa Wisata Sendang Duwur maka kontribusi khususnya terhadap perekonomian masyarakat lokal yang akan diberikan dari desa wisata ini akan lebih optimal ke depannya. Oleh karena adanya hal ini, membuat penulis tertarik untuk mengangkat topik penelitian mengenai kontribusi Desa Wisata Sendang Duwur terhadap ekonomi masyarakat lokal.

Dari latar belakang di atas ditarik rumusan masalah sebagai berikut:
1. Apa keunikan dari produk wisata yang ditawarkan di Desa Wisata Sendang Duwur?

2. Bagaimana perilaku belanja wisatawan di Desa Wisata Sendang Duwur?

3. Bagaimana kontribusi pariwisata Desa Wisata Sendang Duwur terhadap ekonomi masyarakat lokal?

\section{KEPUSTAKAAN}

\section{Konsep Kontribusi Ekonomi Pariwisata}

Menurut Adikampana (2012) kontribusi pariwisata terhadap masyarakat di kategorikan menjadi dua bagian yaitu kontribusi primer dan kontribusi sekunder dimana pembelanjaan pengunjungnya, besarannya ditentukan dari lama tinggal di destinasi.

\section{Konsep Keunikan Produk Wisata}

Menurut Cooper (1993) dalam Suwena dan Widyatmaja (2010) ada empat komponen pendukung daerah tujuan wisata yaitu: 1.) Atraksi. Modal atraksi yang menarik kedatangan wisatawan adalah alam, budaya dan buatan. 2.) Aksesibilitas (Acces) 3.) Fasilitas (Amenities) 4.) Pelayanan Tambahan (Ancillary Service).

\section{Konsep Desa Wisata}

Desa wisata dalam penelitian ini diambil menurut Nuryanti (1993) dalam Arismayanti,dkk (2014).

4. Konsep Perilaku Belanja Wisatawan

Thamrin dan Francis (2012:125) mengatakan keputusan konsumen bermacam-macam tergantung dengan jenis keputusan untuk membeli. Assail membedakan empat jenis perilaku pembelian konsumen dalam penelitian ini konsumen yang dimaksud adalah wisatawan yaitu: (1)Perilaku pembelian kompleks (2)Perilaku pembelian mengurangi ketidaksesuaian (Disonansi) (3)Perilaku pembelian menurut kebiasaan (4)Perilaku pembelian mencari variasi.

\section{Konsep Masyarakat Lokal}

Menurut Damanik dan Weber (2006:23) masyarakat lokal adalah mereka yang merupakan penduduk asli dan bermukim di suatu kawasan wisata. 


\section{METODE PENELITIAN}

Lokasi penelitian ini di Desa Sendang Duwur, Kecamatan Paciran, Kabupaten Lamongan. Untuk memperjelas dan membatasi permasalahan maka dirumuskan ruang lingkup penelitian sebagai berikut:

1. Atraksi wisata natural resources (alami), atraksi wisata budaya dan atraksi buatan.

2. Perilaku pembelian kompleks, perilaku pembelian mengurangi ketidaksesuaian (disonansi), perilaku pembelian menurut kebiasaan, Perilaku pembelian mencari variasi.

3. Kontribusi primer dan kontribusi sekunder.

Jenis data yang digunakan yaitu data kualitatif dan data kuantitatif. Sumber datanya yaitu data primer dan data sekunder. Teknik pengumpulan data yang digunakan adalah menyebarkan kuesioner, observasi, wawancara mendalam, dan dokumentasi. Teknik penentuan sampel menggunakan rumus slovin. Dari rumus slovin tersebut didapatkan 100 responden yang diberi kuesioner. Cara pegambilan sampelnya menggunakan metode Accidental Sampling. Teknik penentuan informan menggunakan purposive sampling. Teknik analisis data menggunakan model alur seperti yang dikemukakan oleh Miles dan Huberman (1984) dalam Yusuf (2014) yang terdiri dari tiga tahap yaitu : reduksi data, display data dan kesimpulan/verifikasi dan teknik analisis statistik deskriptif.

\section{HASIL DAN PEMBAHASAN}

\subsection{Gambaran Umum Desa Sendang Duwur}

Desa Sendang Duwur berada di lereng gunung Amintuno dengan ketinggian 250 DPL (Diatas Permukaan Laut) dengan luas desa sekitar $\pm 24,5$ ha. Mayoritas masyarakat lokalnya bekerja sebagai pengerajin. Kerajinan yang digarap disini mulai dari kerajinan batik, sulam bordir dan perhiasan emas. Sendang Duwur adalah desa yang juga punya sejarah panjang, mulai dari peradaban Hindu hingga peradaban Islam. Ini terbukti dengan adanya berbagai peninggalan benda kuno seperti gapura bersayap, paduraksa, masjid kuno dan lain-lain.

\subsection{Keunikan Produk Wisata Desa Wisata Sendang Duwur}

Di Desa Wisata Sendang Duwur terdapat beberapa atraksi wisata dan mempunyai nilai keunikan yang dapat di nikmati oleh wisatawan dan diklasifikasikan menjadi 3 bagian, yaitu :

\section{Atraksi Natural Resouces (alami)}

Letak Desa Wisata Sendang Duwur yang berada di lereng gunung amintuno dengan ketinggian 250 diatas permukaan air laut menyuguhkan panorama alam yang sangat indah, menyejukkan dan dari atas dapat menyaksikan langsung pemandangan laut jawa. Di Desa Wisata Sendang Duwur juga terdapat bukit kapur. Bukit kapur ini bisa dijadikan sebagai salah satu spot untuk mengabadikan momen pengalaman berwisata di desa ini.

\section{Atraksi Wisata Budaya}

Selain menyajikan pemandangan alam, Desa Wisata Sendang Duwur juga merupakan desa yang mayoritas masyarakat lokalnya bekerja sebagai pengerajin. Anak-anak yang tinggal di Desa Wisata Sendang Duwur sudah diajarkan bagaimana cara membatik sejak usia dini untuk membantu orang tua mereka menyelesaikan pekerjaannya. Biasanya pengunjung yang datang ke Desa Wisata Sendang Duwur adalah anak sekolahan untuk melakukan study tour mengenai batik tulis dan celup. Rokhayatin salah satu pengerajin batik mengatakan bahwa keunikan dari batik sendang duwur ini ada pada desainnya yaitu jenis bunga melati kecil besar yang digabung dengan ciri khas Kabupaten Lamongan yaitu Bandeng Lele, saat ini motifnya mencampurkan desain tradisional dengan modern. Wisatawan yang tertarik dengan kerajinan emas juga dapat melihat pembuatan perhiasan emas langsung di tempat penjual. Uniknya pembuatan emas masih dibuat secara manual (tidak dengan peralatan modern). Proses pembuatan emas 
dengan cara manual memakan waktu satu sampai dua hari, oleh karena itu untuk menyaksikannya wisatawan harus datang saat pengerajin melakukan pameran atau saat mendapatkan pesanan yang banyak.

Di Desa Wisata Sendang Duwur terdapat pula daya tarik wisata religi yaitu makam Sunan Sendang Duwur. Sunan Sendang Duwur merupakan salah satu tokoh penyebar agama Islam. Terdapat peninggalan benda-benda kuno dan situs-situs sejarah di komplek makam. Kayu jati bernilai seni tinggi pun menghiasi dinding-dinding cungkup makam. Ada pula sumur giling meski letaknya di dataran tinggi akan tetapi air didalamnya tidak pernah kering. Selain sumur giling terdapat juga sumur paidon. Menurut cerita penduduk sekitar, tempat ini adalah tempat peludahan R. Noer Rochmat. Air yang ada di dalam sumur paidon ini sering diambil airnya karena orang-orang percaya bahwa air tersebut dapat dipakai untuk berbagai keperluan seperti penyembuhan.

\section{Atraksi Buatan}

Desa Wisata Sendang Duwur memiliki atraksi buatan seperti kesenian Jedor. Jedor merupakan sebuah seni musik yang bernafaskan agama Islam, biasanya ditemukan di daerah yang merupakan jalur penyebaran agama Islam. Dulu hanya dipentaskan saat acara Maulid Nabi SAW saja namun sekarang sering dipentaskan untuk menyambut wisatawan besar, acara-acara adat dan hajatan.

\subsection{Perilaku Belanja Wisatawan di Desa Wisata Sendang Duwur}

Faktor keunikan merupakan salah satu pertimbangan utama wisatawan sebelum melakukan pembelian suatu produk wisata. Berikut ini tabel 4.1 meengenai perilaku wisatawan di Desa Wisata Sendang Duwur yang didapatkan dari survei terhadap 100 orang responden.
Tabel 4.1 Perilaku Belanja Wisatawan di Desa Wisata Sendang Duwur

\begin{tabular}{|c|c|c|c|}
\hline No & $\begin{array}{c}\text { Perilaku Belanja } \\
\text { Wisatawan }\end{array}$ & $\begin{array}{l}\text { Jumlah } \\
\text { (orang) }\end{array}$ & $\begin{array}{c}\text { Persentase } \\
(\%)\end{array}$ \\
\hline 1 & $\begin{array}{l}\text { Perilaku } \\
\text { Pembelian } \\
\text { Kompleks }\end{array}$ & 5 & 5 \\
\hline 2 & $\begin{array}{l}\text { Perilaku } \\
\text { pembelian } \\
\text { mengurangi } \\
\text { ketidaksesuaian } \\
\text { (disonansi) }\end{array}$ & 9 & 9 \\
\hline 3 & $\begin{array}{l}\text { Perilaku } \\
\text { pembelian } \\
\text { menurut } \\
\text { kebiasaan }\end{array}$ & 6 & 6 \\
\hline 4 & $\begin{array}{l}\text { Perilaku } \\
\text { pembelian } \\
\text { mencari variasi }\end{array}$ & 80 & 80 \\
\hline & Jumlah & 100 & 100 \\
\hline
\end{tabular}

Tabel 4.1 menunjukkan tipe wisatawan yang mengunjungi Desa Wisata Sendang Duwur memiliki perilaku pembelian kompleks sebesar $0 \%$, perilaku pembelian mengurangi ketidaksesuaian sebesar $10 \%$, perilaku pembelian menurut kebiasaan sebesar $4 \%$ dan perilaku belanja yang suka mencari variasi dengan persentase jumlah sebesar 86\%. Ini menunjukkan bahwa dominan wisatawan yang datang ke Desa Wisata Sendang Duwur adalah wisatawan berperilaku belanja yang suka mencari variasi. Mereka senang membeli produk yang menurut mereka unik dan tidak dapat mereka beli di tempat lain. Produk yang ditawarkan seperti batikdengan motif khas Lamongan, emas dan bordir yang dijual disana membuat wisatawan ingin mengoleksi dan membawa pulang produk khas Sendang Duwur sebagai cinderamata. Namun disisi lain sekitar $10 \%$ wisatawan memiliki perilaku pembelian mengurangi ketidaksesuaian (disonansi). Konsumen biasanya akan melakukan penawaranpenawaran harga terlebih dahulu di beberapa toko, namun karena harga kerajinan yang dijual hampir sama mereka akan langsung membeli tanpa melakukan penawaran lebih lanjut. Selain itu, dari beberapa wisatawan yang diwawancarai mengatakan bahwa masyarakat Sendang Duwur sangat ramah dan sopan sehingga mereka merasa nyaman berbelanja di 
tempat ini. Hal ini dapat menjadi salah satu factor penarik wisatawan untuk mau berbelanja.

Sebanyak 4\% wisatawan memiliki perilaku pembelian menurut kebiasaan. Wisatawan dengan perilaku ini sudah pernah ke Desa Sendang Duwur sebelumnya sehingga mereka tidak lagi mencari informasi yang ekstensif, mengevaluasi karakteristik mengenai batik, bordir ataupun perhiasan emas yang dijual di desa ini dan tidak membuat keputusan dengan pertimbangan saat membelinya. Dari data diatas dapat disimpulkan bahwa kebanyakan wisatawan yang datang ke Desa Wisata Sendang Duwur adalah wisatawan yang ingin mencari sesuatu yang lain, beda dari biasanya, unik dan bervariasi. Oleh karena itu faktor keunikan menjadi salah satu faktor penting dalam menunjang keputusan pembelian wisatawan. Pengerajin harus tetap mempertahankan nilai keunikan dari produk yang mereka buat agar tetap disukai oleh wisatawan.

\subsection{Kontribusi Pariwisata Desa Wisata Sendang Duwur terhadap Ekonomi Masyarakat Lokal}

Pembelanjaan langsung pengunjung di Desa Wisata Sendang Duwur yang di peroleh dari hasil survei 100 orang pengunjung diketahui bahwa rata-rata pembelanjaan pengunjung per hari sebesar Rp.98.500-. Besar pembelanjaan tersebut terbagi dalam penerimaan pembelanjaan langsung dan tidak langsung atas penyediaan barang dan jasa di Desa Wisata Sendang Duwur. Penerimaan langsung diperoleh dari komponen cinderamata, akomodasi, makanan dan minuman, fasilitas dan lain-lain sedangkan penerimaan tidak langsung diperoleh dari komponen transportasi. Berikut tabel 4.2 dapat dilihat Jumlah pembelanjaan per orang perhari dari penerimaan pembelanjaan langsung dan tidak langsung.
Tabel 4.2 Rata-Rata Pembelanjaan Pengunjung

\begin{tabular}{|c|c|c|c|}
\hline Komponen & $\begin{array}{c}\text { Pembelanjaan } \\
\text { (Rp/orang/ha } \\
\text { ri) }\end{array}$ & $\begin{array}{c}\text { Jumlah } \\
\text { Pengunj } \\
\text { ung } \\
\text { (orang) }\end{array}$ & $\begin{array}{c}\text { Persentase } \\
(\%)\end{array}$ \\
\hline Cinderamata & 76800 & \multirow{6}{*}{100} & 37 \\
\hline Transportasi & 70000 & & 33 \\
\hline Penginapan & 0 & & 0 \\
\hline $\begin{array}{l}\text { Makanan } \\
\text { dan } \\
\text { minuman }\end{array}$ & 36800 & & 18 \\
\hline Fasilitas & 7950 & & 4 \\
\hline Dan lain-lain & 16100 & & 8 \\
\hline Total & 207650 & & 100 \\
\hline
\end{tabular}

Sumber : Laporan Penelitian Lapangan III Tahun 2017

Melalui Tabel 4.2 dapat dilihat komposisi pembelanjaan pengunjung terbesar yang diperoleh dari penerimaaan langsung akan penyediaan barang dan jasa pariwisata di Desa Wisata Sendang Duwur adalah dari komponen cinderamata sebesar Rp.76.800,- atau sebesar 37 \%. Diposisi kedua komponen makanan dan minuman sebesar Rp.36.800,- atau sekitar 18\% dari rata - rata pembelanjaan pengunjung. Saifulloh selaku Ketua Pokdarwis (Kelompok Sadar Wisata) Desa Wisata Sendang Duwur mengatakan bahwa jarang wisatawan yang mau menginap di Desa Sendang Duwur karena biasanya mereka hanya melakukan kunjungan singkat saja. Oleh karena itu, tidak ada penginapan yang dibangun di desa, namun jika suatu saat ada wisatawan yang ingin menginap ada beberapa rumah warga yang kamarnya boleh di tempati oleh wisatawan dan wisatawan itu sendiri boleh mengikuti kegiatan bersama keluarga itu. Ini juga yang menyebabkan mengapa pembelanjaan pengunjung untuk komponen penginapan sebesar $0 \%$ atau dapat dikatakan tidak adanya pembelanjaan pengunjung untuk komponen penginapan karena mereka hanya melakukan kunjungan singkat yang dapat dilakukan dalam sehari saja.

Komponen fasilitas mendapat perolehan sebesar Rp.7950,- atau sekitar $4 \%$ rata-rata pembelanjaan pengunjung. Biaya yang di keluarkan pada komponen fasilitas ini adalah untuk penggunaan fasilitas seperti toilet dan parkir. Dan lain- 
lain disini diperoleh dari wisatawan yang mengeluarkan uangnya untuk sumbangan/donasi terhadap perawatan dan kebersihan makam Sunan Sendang Duwur ataupun wisatawan yang ingin memberi sumbangan kepada pengerajin yang sudah mengizinkan melihat bagaimana cara membuat batik, bordir maupun emas. Tak jarang ada pengunjung yang memberi sembako sebagai bentuk terimakasih. Sedangkan untuk penerimaan pembelanjaan pengunjung tidak langsung diperoleh dari komponen transportasi yaitu sebesar Rp. 77.000,- atau sekitar 33\% dari rata-rata pembelanjaan pengunjung. Hasil ini diperoleh dari siswa-siswi yang melakukan studytour dan wisatawan yang mengunjungi daya tarik wisata makam Sunan Sendang Duwur baik dari dalam maupun luar Kabupaten Lamongan yang rata-rata memilih pengaturan perjalanan dengan menyewa bus kecil atau mnggunakan agen perjalanan. Jasa travel agent ini dibutuhkan karena lokasi desa yang cukup sulit ditemukan bagi wisatawan yang datang dari luar Kabupaten Lamongan dan dengan menggunakan jasa travel agent dapat mengangkut wisatawan yang datang berkelompok.

Dari penjabaran diatas menunjukkan bahwa Desa Wisata Sendang Duwur belum berkontribusi secara optimal dalam meningkatkan perekonomian masyarakat lokalnya pasalnya pembelanjaan pengunjung yang besarannya ditentukan oleh lama tinggal tidak dapat digunakan karena tidak adanya kontribusi yang diberikan dari komponen penginapan. Kontribusi terhadap ekonomi masyarakat yang dapat dirasakan langsung oleh masyarakat lokal sejauh ini dari penerimaan pembelanjaan langsung atas barang dan jasa pariwisata di Desa Wisata Sendang Duwur adalah dari komponen makanan dan minuman. Kondisi ini dapat memberikan peluang bisnis kepada masyarakat Desa Wisata Sendang Duwur untuk membuka usaha warung makan yang menyediakan kuliner khas Desa Wisata Sendang Duwur yaitu nasi mutuk. Jika dilihat dari penerimaan pembelanjaan tidak langsung dari komponen transportasi dapat memberikan peluang bisnis untuk membuka jasa travel agent di Desa Sendang Duwur. Untuk meningkatkan jumlah wisatawan yang menginap sebaiknya dilakukan promosi atau sediakan paket wisata yang dapat membuat wisatawan tertarik untuk menginap di Desa Wisata Sendang Duwur agar kontribusi pariwisata Desa Wisata Sendang Duwur terhadap ekonomi masyarakat lokal dapat dirasakan oleh segenap elemen masyarakat.

\section{PENUTUP}

\subsection{Simpulan}

Desa Wisata Sendang Duwur memiliki produk wisata yang unik mulai dari :

1.) Atraksi alamnya seperti panorama alam yang indah, menyejukan dan dapat melihat pemandangan laut jawa serta memiliki bukit kapur yang dapat menjadi spot foto untuk mengabadikan momen pengalaman berwisata di tempat ini. 2.) Atraksi budaya seperti hasil kerajinan tangan khas Sendang Duwur yaitu batik, bordir dan perhiasan emas serta daya tarik wisata religinya yaitu Makam Sunan Sendang Duwur yang memiliki peninggalan situs-situs sejarah perpaduan kebudayaan Hindu dan Islam. 3.) Desa Wisata Sendang Duwur memiliki atraksi buatan seperti kesenian Jedor.

Dominan perilaku berlanja wisatawan yang datang ke Desa Wisata Sendang Duwur adalah wisatawan yang ingin mencari sesuatu yang lain, beda dari biasanya, unik dan bervariasi. Namun Desa Wisata Sendang Duwur belum berkontribusi secara optimal dalam meningkatkan perekonomian masyarakat lokalnya pasalnya pembelanjaan pengunjung yang besarannya ditentukan oleh lama tinggal tidak dapat digunakan karena tidak adanya kontribusi yang diberikan dari komponen penginapan. Kontribusi ekonomi bagi masyarakat lokal yang didapatkan dari penerimaan langsung pembelanjaan pengunjung sejauh ini yang bisa diharapkan adalah dari komponen cinderamata dengan persentase rata-rata pembelanjaan pengunjung sebesar 37\%. Dan jika dilihat dari penerimaan pembelanjaan tidak langsung dari komponen transportasi dengan persentase total rata-rata pembelanjaan pengunjung sebesar 33\%. 


\subsection{Saran}

1. Diperlukannya perhatian khusus dari pemerintah bagi kepariwisataan Desa Wisata Sendang Duwur seperti melakukan promosi yang gencar agar wisatawan dari luar Kabupaten Lamongan bahkan mancanegara lebih mengetahui keberadaan Desa Wisata Sendang Duwur.

2. Dilihat dari tipe perilaku belanja wisatawan yang suka mencari variasi dapat memberikan ide peluang bisnis seperti membuka toko cinderamata atau art souvenir. Dapat juga membangun penginapan agar mendorong minat wisatawan untuk menetap di desa.

3. Masyarakat lokal yang mayoritas bekerja sebagai pengerajin harus tetap mempertahankan keunikan produknya karena wisatawan menyukai nilai unique selling dari produk pengerajin dan diberikan pelatihan agar masyarakat sadar wisata dan terlibat dalam kepariwisataan di Desa Wisata Sendang Duwur.

\section{DAFTAR PUSTAKA}

Abdullah. Thamrin dan Francis Tantri. 2012. Manajemen Pemasaran. Jakarta : PT. Raja Grafindo Persada.

Adikampana, I Made. 2012. Optimalisasi Kontribusi Pariwisata Ceking Terhadap Ekonomi Masyarakat Lokal. Jurnal Analisis Pariwisata Volume 2 No. 1 Hal 109-222.

Arismayanti, Ni Ketut, Saptono Nugroho dan I Putu Sudana. 2014. Strategi Pengembangan Desa Wisata Berbasis Masyarakat Di Desa Adat Penglipuran Bangli. Jurnal Analisis Pariwisata Volume 14 No.2 Hal 47-66

Darmaputra, I Nyoman dan Pitana I Gde. 2010. Pariwisata Pro-Rakyat Meretas Jalan Mengentaskan Kemiskinan di Indonesia. Jakarta : Kementrian Kebudayaan dan Pariwisata

Suwena, I Ketut dan I Gusti Ngurah Widyatmaja. 2010. Pengetahuan Dasar Ilmu Pariwisata. Denpasar : Udayana University Press.

Yusuf, Muri. 2014. Metode Penelitian Kuanitatif, Kualitatif \& Penelitian Gabungan. Jakarta : Prenada Media Group. 